\title{
Sarcomatoid Dedifferentiation in Renal Cell Carcinoma: From Novel Molecular Insights to New Clinical Opportunities
}

\author{
Véronique Debien ${ }^{1,2,+}$, Jonathan Thouvenin ${ }^{1,2, \dagger}$, Véronique Lindner ${ }^{3}$, Philippe Barthélémy ${ }^{2}$, \\ Hervé Lang ${ }^{4}$, Ronan Flippot ${ }^{5, \ddagger}$ and Gabriel G. Malouf ${ }^{1,2, *, \ddagger}$ \\ 1 Department of Oncology, Institut de Cancérologie de Strasbourg, Hôpitaux Universitaires de Strasbourg, \\ Université de Strasbourg, 67200 Strasbourg, France; veronique.debien@chru-strasbourg.fr (V.D.); \\ jonathan.thouvenin@chru-strasbourg.fr (J.T.) \\ 2 Department of Cancer and Functional Genomics, Institute of Genetics and Molecular and Cellular Biology, \\ CNRS/INSERM/UNISTRA, 67400 Illkirch, France; p.barthelemy@icans.eu \\ 3 Department of Pathology, Centre Hospitalier Universitaire Régional de Strasbourg, 67200 Strasbourg, France; \\ veronique.lindner@chru-strasbourg.fr \\ 4 Department of Urology, Centre Hospitalier Universitaire Régional de Strasbourg, 67000 Strasbourg, France; \\ herve.lang@chru-strasbourg.fr \\ 5 Department of Cancer Medicine, Gustave Roussy, 94800 Villejuif, France; ronan.flippot@gustaveroussy.fr \\ * Correspondence: g.malouf@icans.eu or gabriel.malouf@chru-strasbourg.fr; Tel.: +33-368-767-217 \\ + These authors contributed equally to this paper. \\ $\ddagger$ These authors contributed equally to this paper.
}

Received: 29 October 2019; Accepted: 20 December 2019; Published: 31 December 2019

\begin{abstract}
Sarcomatoid features in renal cell carcinoma (RCC) have long been associated with dismal prognosis and poor response to therapy, while biological mechanisms underpinning sarcomatoid dedifferentiation remained obscure. Several efforts have been conducted to break down the molecular profile of sarcomatoid RCC and investigate different targeted therapeutic approaches. Mutations enriched for in sarcomatoid RCC involve, notably, TP53, BAP1, cell cycle, and chromatin-remodeling genes. The immunological landscape of these tumors is also gradually being uncovered, showing frequent expression of programmed cell death ligand-1 (PD-L1) and high levels of tumor-infiltrating lymphocytes. These features may be major determinants for the activity of immune checkpoint inhibitors in this population, which has been confirmed by retrospective studies and subgroup analyses of large randomized phase 3 trials. Combinations based on PD-1/PD-L1 inhibition have demonstrated response rates and complete responses in $>50 \%$ and $>10 \%$ of patients in the first-line metastatic setting, respectively, with median overall survival exceeding two years. This remarkable improvement in outcomes effectively establishes immune checkpoint inhibitor combinations as a new standard of care in patients with sarcomatoid RCC. New research fields, including epigenetic regulations and tumor-microenvironment interactions, may further sharpen understanding of sarcomatoid RCC and advance therapeutic developments.
\end{abstract}

Keywords: renal cell carcinoma; sarcomatoid; immunotherapy

\section{Introduction}

Renal cell carcinoma (RCC) is the third most frequent urologic malignancy, affecting more than 400,000 patients each year [1]. Approximately half of these patients will present with metastatic disease, either at diagnosis or after initial treatment of localized disease. While five-year overall survival (OS) rates do not exceed $15 \%$ in the Western world [2], vascular endothelial growth receptor 
(VEGFR)-directed therapies and immune checkpoint inhibitor combinations have progressively improved the prognosis of these tumors.

The landscape of RCC remains largely heterogeneous. Most RCCs (75\%) consist of clear-cell subtypes, while the remaining $25 \%$ consist of different tumor subtypes grouped under the umbrella term of non-clear-cell RCC [3]. Non-clear-cell RCCs are usually more aggressive diseases than clear-cell RCCs [4] and include papillary, chromophobe, collecting duct, translocation, and medullary carcinomas. Sarcomatoid dedifferentiation is a histological feature that can be found in approximately $10 \%$ of tumors in any RCC subtype and confers aggressive behavior characterized by swift progression and dismal outcomes [5,6]; however, molecular and immunologic determinants of sarcomatoid dedifferentiation remain unclear. As survival commonly remains $<12$ months in patients with sarcomatoid RCC (sRCC) treated in the era of targeted molecular therapies [5], it is essential to improve our understanding of the natural history of sRCC and evaluate new therapeutic avenues in this aggressive disease.

The clinical and translational research field of sRCC is hopefully growing fast. Clinical trials of immune checkpoint inhibitors have demonstrated encouraging activity results, while an increasing number of studies have continued to provide new insights into sRCC biology. As the landscape of sRCC is being redefined, this review aims to explore the most recent advances in molecular and immune characterization of sRCC and discuss how new therapeutic developments can transform the standard of care in this population.

\section{Pathological Implications of Sarcomatoid Renal Cell Carcinoma}

sRCC is a pathological entity defined by the presence of spindle-shaped cells in a varying proportion of the tumor area, which can account for a sarcoma-like aspect [7]. Indeed, sarcomatoid cells in RCCs have been reported to be engaged in epithelial-mesenchymal transition (EMT) [8,9], expressing mesenchymal markers including N-cadherin and vimentin, while expression of the epithelial marker e-cadherin is lost. Sarcomatoid cells also harbor increased Snail levels, a transcription factor enabling the expression of genes involved in EMT [10]. As such, the main differential diagnoses of sRCC with extensive sarcomatoid dedifferentiation are retroperitoneal leiomyosarcoma or liposarcoma. Immunohistochemistry assays may refine diagnosis, with expression of epithelial markers as keratin, cytokeratin 7, or epithelial membrane antigen (EMA) with expression of PAX8, CD10, and CAIX accounting for a renal origin [11,12]. Most often, however, sarcomatoid areas of sRCC coexist with their parent histology to make for an easier diagnosis. Rarely, some RCCs might harbor low-grade spindle cell proliferation, an entity that is distinct from sRCC and less aggressive [13].

Among aggressive subsets of RCCs, the International Society of Urologist Pathologists (ISUP) classification distinguishes sRCC and rhabdoid $\mathrm{RCC}^{1.7}$. Any of these features can be present in RCC regardless of the histological subtype, and they may coexist. The presence of sarcomatoid or rhabdoid features in any proportion would classify any clear-cell or papillary RCC as an ISUP grade 4 tumor [14]. Some sRCCs with extensive sarcomatoid dedifferentiation encompassing the whole tumor without clear evidence of any parent histology may be considered as unclassified RCCs [15]. The occurrence of sarcomatoid dedifferentiation may vary according to the parent histology. Sarcomatoid features have thus been reported in $9 \%$ of chromophobe RCCs, $5 \%$ of clear-cell RCCs, and $2 \%$ of papillary RCCs in a large retrospective study [16].

The aggressiveness of sRCC is highlighted by the high frequency of distant metastases at diagnosis, reported in approximately two-thirds of patients with sRCC of any histology compared to approximately $30 \%$ of patients without sarcomatoid features $[17,18]$. The proportion of sarcomatoid features also plays a role in the definition of prognosis, as a higher percentage has been shown to be associated with higher risk of relapse in a localized setting, and worse overall survival $[17,19]$. While the quantification of sarcomatoid features is an important prognostic indicator, accurate evaluation might be compromised by the extent of tumor heterogeneity. It has been shown that biopsies are up to two-fold less likely to identify sarcomatoid features compared to the analysis of nephrectomy specimens [20], while some tumors may harbor sarcomatoid features exclusively in distant metastases [19], which may lead to 
an underestimation of the prevalence of sRCC in kidney cancer patients. It is yet unknown whether sarcomatoid dedifferentiation can also occur as a late event upon disease progression, an element that could have prognostic and therapeutic implications for late-stage disease.

\section{Molecular Landscape of Sarcomatoid Renal Cell Carcinoma}

Multiple studies have aimed to unravel the molecular picture of sRCC and events leading to sarcomatoid dedifferentiation, an important effort considering the low incidence of these tumors and the heterogeneity of parent histologies. The theory of a common cell of origin for the epithelial and sarcomatoid components in sRCC has been confirmed by several studies. As demonstrated in sRCC of clear-cell type, sarcomatoid and epithelial components share most copy number alterations, $\mathrm{X}$ chromosome inactivation patterns, and single nucleotide variants [21-23]. Notably, clear-cell sRCC harbor a lower frequency of $3 p$ loss, locus of the VHL gene, but also of chromatin remodeling genes BAP1 and PBRM1 [22,24]. More surprisingly, clear-cell sRCC are also devoid of 9p and 14q alterations usually associated with poor prognosis and high grade in clear-cell RCC [22].

Likewise, the transcriptomic profile of clear-cell sRCC harbors differences compared to that of nonsarcomatoid clear-cell RCC, with activation of pathways involved in aggressiveness and epithelial mesenchymal transition. It has been shown that clear-cell sRCCs harbor higher expression of VEGF and TGF $\beta 1$ pathways, while the TP53 pathway is repressed [22,24]. Clear-cell sRCC expression profile is also enriched in genes involved in the poor prognostic signature $\mathrm{ccB}$ [25] compared to non sarcomatoid clear-cell RCC, consistent with their clinical aggressiveness [22]. A few studies have pinpointed differences between the transcriptional profiles of sarcomatoid and epithelial components in a single tumor [22-24]. These have shown that several genes involved in EMT may have increased expression in the sarcomatoid component of clear-cell sRCC, which could account for the mesenchymal phenotype of these cells [22]. Additional insights from an independent cohort showed that sarcomatoid components might harbor increased Aurora kinase-1 expression, suggested to drive malignancy by increasing mammalian target of rapamycin (mTOR) activation [26].

More differences may be found in exploring the genomic alterations of sRCC, which reveals several potential drivers of sarcomatoid dedifferentiation (Figure 1). A study of 26 sRCCs using tumor microdissection from mixed parent histologies by targeted sequencing showed that sRCC harbored frequent mutations in TP53,VHL, CDKN2A, and NF2 in 42\%, 35\%, 27\%, and 19\% of tumors, respectively [27]. TP53 mutations were not associated with a specific histological subtype and were significantly enriched compared to non sarcomatoid RCC cohorts as those were found in only $2 \%$ of clear-cell RCC from the Cancer Genome Atlas (TCGA) dataset [28]. Likewise, NF2 mutations only involved 1\% of clear-cell RCC from the TCGA. Additional studies have depicted the mutational landscape of sRCC with focus on specific histologies. Whole-exome sequencing of sRCC from clear-cell origin confirmed the high prevalence of TP53 alterations in two independent cohorts $[23,24]$. Additional recurrent mutations in sRCC from clear-cell origin include Hippo regulators FAT1/2/3 and chromatin remodeling gene $A R I D 1 A$ [23] as well as tumor suppressor PTEN and TGF $\beta$ regulator RELN [24]. Comparison of sarcomatoid and epithelial components of clear-cell sRCC hint at a higher mutational burden in the sarcomatoid component and a higher frequency of TP53, BAP1, and ARID1A mutations [23]. Mutations in those three genes have been described as mutually exclusive, suggesting potential driver events [23]. TP53 alterations have also been described in sRCC from papillary origin, along with alterations of Hippo member NF2, while mutations in RELN are reported to be enriched in sRCC regardless of the parent histology [24]. 
High lymphocyte infiltration High tumour cells PD-L1 expression
Tumour suppressor genes inactivating mutations / loss

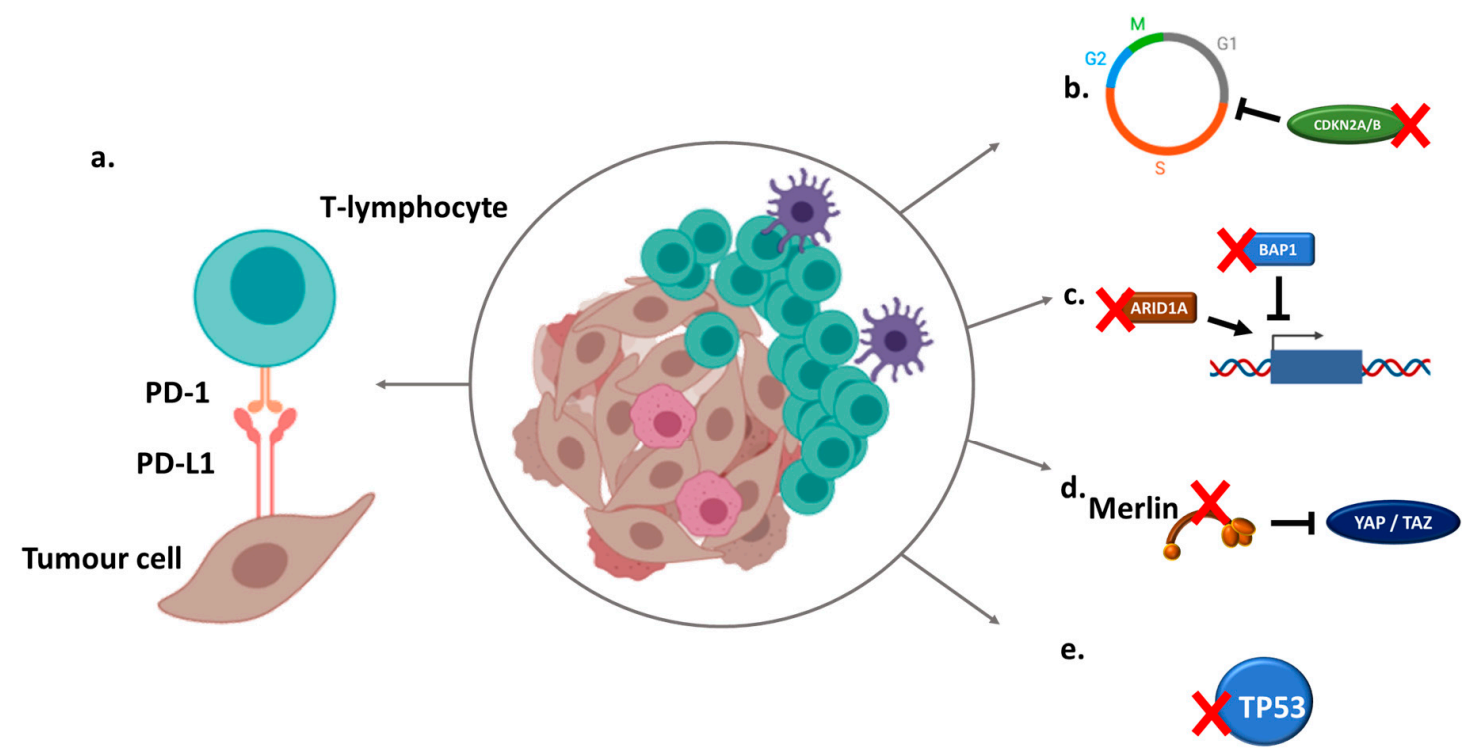

Figure 1. Immunologic and genomic hallmarks of sarcomatoid dedifferentiation in renal cell carcinoma (RCC). (a) Sarcomatoid renal cell carcinomas (sRCCs) are associated with higher programmed cell death ligand-1 (PD-L1) expression on tumor cells and higher lymphocyte infiltration. (b) Recurrent alterations of cell cycle inhibitors $C D K N 2 A / B$ promote cell proliferation and epithelial/mesenchymal transition. (c) Loss of chromatin-remodeling genes BAP1 and ARID1A induce genome-wide expression deregulation. (d) Loss of Merlin, encoded by the NF2 gene, promotes Hippo pathway activation, leading to growth and aggressiveness. (e) Loss of tumor suppressor gene TP53 favors survival and proliferation.

While these studies do not provide a unique explanation for the emergence of sarcomatoid features, recurrent mutations might participate in driving this aggressive phenotype, along with other deregulations of cellular processes. Likewise, an updated analysis of the TCGA dataset identified a subset of metabolically divergent chromophobe RCC, characterized by low expression of genes involved in the Krebs cycle, the electron transport chain, repression of the AMPK, and overexpression of genes involved in the ribose synthesis [29]. This signature was associated with poor outcomes and, strikingly, four of the six patients $(67 \%)$ with metabolically deficient chromophobe RCC had a disease that presented with sarcomatoid dedifferentiation. Other particular phenotypes may include hypermutated tumors, which was found in 2 of $21(10 \%)$ clear-cell sRCC in a single institution cohort [23]; this phenotype had not been encountered in the larger, non-sRCC TCGA dataset. This hypermutated phenotype was due to somatic $M S H 2$ and POLE mutations, which could have favored the emergence of the sarcomatoid phenotype in these tumors.

A better understanding of sarcomatoid transformation may also be achieved by studying aggressive unclassified RCC (uRCC), which may include tumors with an exclusive sarcomatoid or rhabdoid component [15]. A molecular study of 62 uRCC identified a NF2-deficient subgroup encompassing $26 \%$ of tumors and characterized by worse outcomes [30]. This subgroup of tumors also displayed more frequent SETD2 alterations and 3p loss. As such, alterations of the Hippo pathway may be an important event for tumor aggressiveness and progression regardless of pathological features of RCC, which may have translational and therapeutic relevance for targeted approaches [31].

Several aspects of sRCC as a disease remain unknown. The relationship between molecular heterogeneity and response to therapy is yet to be defined, while the natural history of the disease may also be heavily influenced by the tumor microenvironment. In the era of immune checkpoint inhibitors, 
immune infiltration and exploration of immune markers will be key factors for the management of sRCC.

\section{The Immune Microenvironment of Sarcomatoid Renal Cell Carcinoma}

The biology of sRCC may account for a particular immune context when compared to non-sRCC (Figure 1). The expression of the immune checkpoint programmed cell death ligand-1 (PD-L1), promoting immune tolerance and targeted by several immune checkpoint inhibitors, is increased on the surface of sRCC cells compared to non-sRCC ones (Figure 2) regardless of parent histology and non-sRCC tumor grade [32,33]. Interestingly, there is a clear difference in PD-L1 expression between the different components of sRCC. While sarcomatoid components of sRCC display the highest PD-L1 expression, levels of PD-L1 expression on epithelial components of sRCC are similar to those of non-sRCC [32]. As such, PD-L1 expression levels are associated with the extent of sarcomatoid dedifferentiation [33]. Data from prospective clinical trials have confirmed the high levels of PD-L1 expression on sRCC of clear-cell type, with $\geq 50 \%$ of patients displaying PD-L1 expression $\geq 1 \%$ on tumor cells [34] or immune-infiltrating cells [35,36].

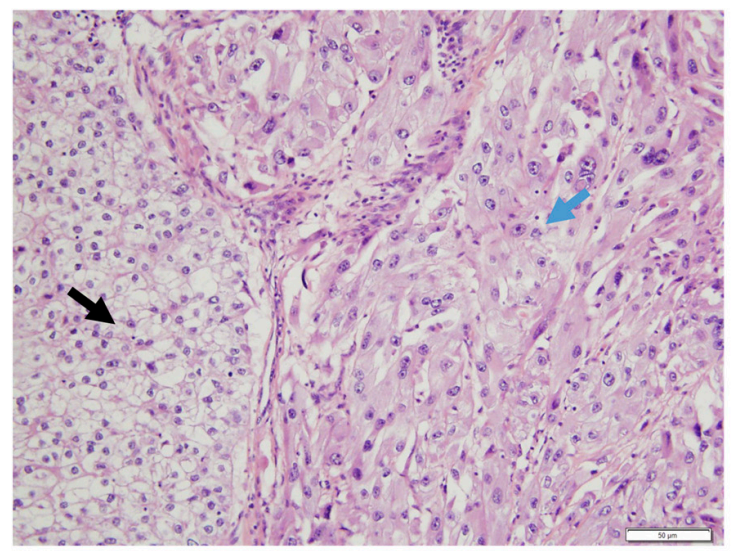

a

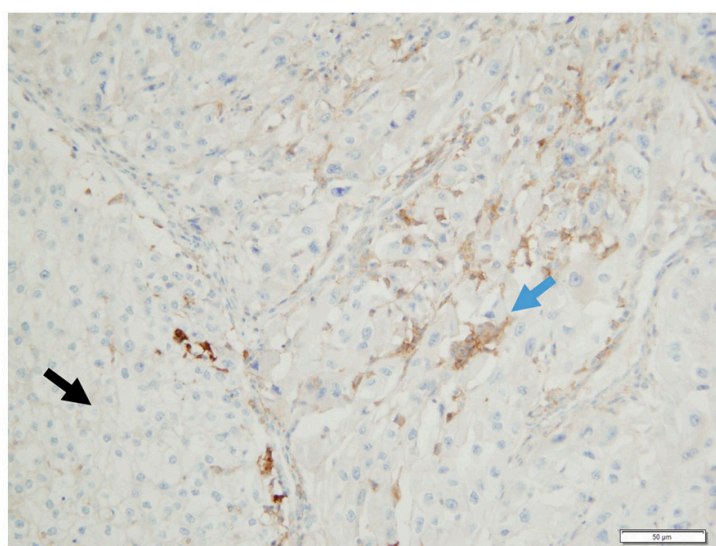

b

Figure 2. (a) Interface between areas of classical clear-cell carcinoma (black arrow) and its sarcomatoid component (blue arrow), Hematoxylin Eosin staining. (b) A higher density of tumor-infiltrating mononuclear inflammatory cells expressing PD-L1 is observed in the SRCC area compared to the clear-cell RCC one (monoclonal mouse antibody clone 22C3, hematoxylin counter staining). In this case, there is no PD-L1 expression on tumor cells.

sRCC also present with a higher density of tumor-infiltrating lymphocytes (TILs) compared to non-sRCC regardless of histology (Figure 2), and most of these lymphocytes have been reported to express PD-1 [33]. Up to $40 \%$ of sarcomatoid components of 118 sRCC from any histology were reported to harbor both PD-L1 expression and TIL infiltration in a single center study, compared to $8 \%$ of epithelial components of sRCC and 1\% of control clear-cell RCCs [32]. This pattern has been suggested to be associated with immune resistance and may confer sensitivity to immune checkpoint inhibitors. This is corroborated by the high concomitant expression of PD-L1 in tumor cells and PD-1 in TIL, which was reported in up to $50 \%$ of sRCC of any subtype compared to less than $5 \%$ of non-sRCC in another retrospective cohort, suggesting that the PD-1/PD-L1 axis is active in sRCC [33].

Molecular studies provide additional basis for the immunogenic potential of sRCC. Study of gene expression signatures in the IMmotion151 phase 3 trial of atezolizumab plus bevacizumab versus sunitinib reported that clear-cell sRCC had a higher T-effector signature (54\% versus $40 \%$ ), a lower angiogenesis signature (34\% versus 65\%), and a higher expression of PD-L1 (63\% versus $39 \%$ ) compared to nonsarcomatoid clear-cell RCC [37]. Along with concordant clinical outcomes showing potent 
activity of atezolizumab plus bevacizumab in this population (Table 1), these data corroborate the immunogenicity of these tumors and the potential for immune-directed approaches.

Table 1. Activity of immune checkpoint inhibitors in clear-cell sRCC from subgroup analyses of phase 3 trials.

\begin{tabular}{|c|c|c|c|c|c|c|c|}
\hline Trials & Population & Agents & $\mathbf{N}$ & ORR & CRR & $\begin{array}{c}\text { Median } \\
\text { PFS }\end{array}$ & Median OS \\
\hline \multirow{3}{*}{ Keynote-426 } & \multirow{3}{*}{ Intent-to-treat } & pembrolizumab + axitinib & 51 & $59 \%$ & $13 \%$ & 8.4 months & NR \\
\hline & & vs. & vs. & vs. & vs. & vs. & vs. \\
\hline & & sunitinib & 54 & $32 \%$ & $2 \%$ & NR & NR \\
\hline \multirow{3}{*}{ CheckMate-214 } & \multirow{3}{*}{$\begin{array}{l}\text { IMDC poor or } \\
\text { intermediate risk }\end{array}$} & nivolumab + ipilimumab & 60 & $57 \%$ & $18 \%$ & 8.4 months & 31.2 months \\
\hline & & vs. & vs. & vs. & vs. & vs. & vs. \\
\hline & & sunitinib & 52 & $19 \%$ & $0 \%$ & 4.9 months & 13.6 months \\
\hline \multirow{3}{*}{ IMmotion151 } & \multirow{3}{*}{ Intent-to-treat } & atezolizumab + bevacizumab & 68 & $49 \%$ & $10 \%$ & 8.3 months & 21.7 months \\
\hline & & vs. & vs. & vs. & vs. & vs. & vs. \\
\hline & & sunitinib & 74 & $14 \%$ & $3 \%$ & 5.3 months & 15.4 months \\
\hline \multirow{3}{*}{$\begin{array}{l}\text { JAVELIN Renal } \\
101\end{array}$} & \multirow{3}{*}{ Intent-to-treat } & avelumab + axitinib & 47 & $47 \%$ & $4 \%$ & 7.0 months & \multirow{3}{*}{ NA } \\
\hline & & vs. & vs. & vs. & vs. & vs. & \\
\hline & & sunitinib & 61 & $21 \%$ & $0 \%$ & 4.0 months & \\
\hline
\end{tabular}

Abbreviations: ORR: objective response rate, CRR: complete response rate, PFS: progression-free survival, OS: overall survival, NR: not reached, NA: not available, CPS: combined positive score.

Tumor mutational burden is another hallmark that has been suggested to predict outcomes to immunotherapy in solid tumors through the formation of immunogenic neoantigens that would elicit antitumor immune response [38]. Data on sRCC remain equivocal. In a large retrospective study based on targeted sequencing of 79 sarcomatoid or rhabdoid RCC from any parent histology, mutational burden was not significantly different from nonsarcomatoid and nonrhabdoid tumors [39]. While a higher rate of somatic mutations has been described in unselected sRCC from another small dataset, these did not significantly affect relevant cancer-related genes [24]. Some data suggest that TP53 alterations may be associated with higher mutational load, but the clinical relevance is yet unclear [27].

Overall, there is consistent data demonstrating that sRCC may constitute a more immunogenic subtype of cancer than non-sRCC regardless of histology, which provide an interesting basis for the study of immune checkpoint inhibitors in these populations. Additional exploration of the immune microenvironment [40], specific mutation profiles including small insertions and deletions [41], and expression of other immune checkpoints [42] should be pursued to improve our understanding of sRCC immunity.

\section{Improving Therapeutic Strategies through Immune Checkpoint Inhibition}

Therapeutic management of sRCC shares similarities with that of non-sRCC. In a context of nonresectable or metastatic disease, patients have so far been treated with systemic therapies based on VEGFR-targeted agents. Data from patients treated with sunitinib and sorafenib, however, show very limited efficacy, with objective response rates (ORR) below $20 \%$ and median progression-free survival (PFS) and OS below 6 and 12 months, respectively [43]. Additional chemotherapy-based strategies have been used, assuming that antimitotic agents would be effective against this highly proliferative disease. In phase 2 trials, combination of gemcitabine with doxorubicin [44] as well as gemcitabine plus capecitabine and bevacizumab [45] demonstrated some activity regardless of the histological subtype of sRCC, with ORR between $16 \%$ and $20 \%$, PFS of 3.5 to 5.5 months, and OS of 8.8 to 12 months. More recently, the combination of gemcitabine and sunitinib showed mild antitumor activity in unselected sRCC with an ORR of $26 \%$ and PFS and OS of 5 and 10 months, respectively. Subgroup analyses showed an improved response rate in tumors with more than $10 \%$ of sarcomatoid features and improved survival in patients with poor-risk disease [46].

These poor outcomes may be improved by immune checkpoint inhibitors, which has become the standard of care in patients with clear-cell RCC in monotherapy or combination. Notably, nivolumab plus ipilimumab [47] and pembrolizumab plus axitinib [48] have both demonstrated improved OS in intermediate/poor risk patients and all comers, respectively, while atezolizumab plus bevacizumab [37] 
and avelumab plus axitinib [47] demonstrated PFS improvement compared to sunitinib in the first-line metastatic setting. First subgroup analyses, including patients with sarcomatoid tumors, are being reported with promising efficacy results (Table 1 ).

The Keynote-426 trial assessing the pembrolizumab plus axitinib combination and the JAVELIN Renal 101 trial of avelumab plus axitinib both demonstrated improved outcomes in patients with clear-cell sRCC compared with sunitinib [36,49]. The ORR with those combinations were strikingly high at $59 \%$ and $47 \%$, with complete responses (CR) in $12 \%$ and $4 \%$ of patients, respectively. These data translated into increased PFS compared to sunitinib with hazard ratios (HR) of 0.54 (95\% confidence interval (CI) 0.29-1.00) and 0.57 (95\% CI 0.32-1.00) for OS, respectively. Similarly, interesting results were reported with the IMmotion151 trial, which evaluated the combination of atezolizumab plus bevacizumab in the same population. An ORR of $49 \%$, including a complete response rate of $10 \%$, and a HR for PFS of 0.52 (95\% CI 0.34-0.79) and 0.64 (95\% CI 0.41-1.01) in sRCC were reported [35].

The combination of two immune checkpoint inhibitors may also provide impressive results in sRCC patients, as demonstrated by the CheckMate-214 study of nivolumab plus ipilimumab. In patients with intermediate or poor-risk clear-cell sRCC, PFS and OS were improved in the experimental arm, with HR of 0.61 (95\% CI 0.38-0.97) and 0.55 (95\% CI 0.33-0.90), respectively, compared to sunitinib. Importantly, the ORR achieved by the combination of nivolumab plus ipilimumab was as high as $57 \%$, with an impressive proportion $(18 \%)$ of patients achieving complete response (Table 1$)$. These results are encouraging as complete response to immunotherapy has been recently suggested to be a potential surrogate marker for very long-term survival [50].

Additional data stems from phase 2 trials spanning across uncommon histologies. In a phase 2 trial of atezolizumab plus bevacizumab, patients with clear-cell RCC and sarcomatoid dedifferentiation $>20 \%$ had an ORR of 50\% [34]. Data from the cohort B of the Keynote-427 study evaluating pembrolizumab monotherapy showed an ORR of $42 \%$ in patients with sRCC of non-clear-cell subtypes [51].

Prospective clinical trial data thus show convincing efficacy of immune checkpoint inhibitors in sRCC patients and is in line with translational work suggesting that sRCC may be immune-reactive tumors. The use of immunotherapy combinations should be considered as standard of care in these populations, while biomarker analyses are awaited to better inform patient selection.

\section{Perspectives}

The study of sRCC has become a dynamic field, sparking hope for sustained improvement in outcomes in this aggressive subset of tumors. It is now established that sRCC are immunologically "hot" tumors that demonstrate excellent responses to immune checkpoint inhibitors and prolonged survival with combination-based strategies. Current efforts to unravel the molecular landscape of these tumors might help develop targeted strategies to overcome resistance to current therapies.

Many questions about sRCC biology have yet to be answered to get to this point. The mechanisms underlying sarcomatoid dedifferentiation are still mostly unknown. Despite evidence of recurrent genomic alterations, those are not specific to sRCC and may not be enough to drive this aggressive phenotype. In addition, the relevance of these alterations for targeted therapies has yet to be investigated in dedicated clinical trials. More answers could lie in epigenetics and regulatory processes that trigger transcriptional programs involved in sarcomatoid transformation. Such processes may be impacted by the cellular context, including alterations of cellular metabolism [29] as well as interactions between tumor cells and their surrounding microenvironment [52]. The noncoding genome also needs to be explored in the future. In particular, alterations affecting regulatory RNAs may impact cell machinery and disrupt gene expression toward epithelial-mesenchymal transition [53]. The impact of parent histologies on such cellular processes also needs to be determined as the diversity of RCC subtypes may account for wide genetic and epigenetic variations.

The encouraging results of immune checkpoint inhibitor combinations in a disease known to be refractory to past standard of care therapies brings new optimism in the field. Biomarkers of response to therapy remain to be found, similar to non-sRCC, where PD-L1 expression [54], tumor mutational 
burden [38], or gene expression profiles [55] have yet to prove their clinical utility to accurately stratify patients. Additional combinations using modified proinflammatory cytokines [56] or novel checkpoint inhibitors [57] have the potential to further improve the efficacy of PD-1/PD-L1-based regimens. Approaches based on multimodal therapy, such as combining stereotactic radiation therapy to bolster immunity, could be interesting to explore in these inflamed tumors [58]. Opportunities for targeted therapies should also be evaluated: cell cycle inhibitors could be interesting in tumors with alterations of cell cycle proteins [59]; approaches targeting chromatin remodeling complexes in tumors already deficient in one or multiple chromatin-remodeling genes, such as ARID1A, could promote synthetic lethality, as demonstrated in other solid tumors [60]; NF2-deficient tumors could be targeted in preclinical models by YAP/TAZ depletion associated with MEK inhibition [31]. The progress made in the metastatic setting may also translate into localized disease. Multiple trials are ongoing for evaluating immune checkpoint inhibition perioperatively, including nivolumab (NCT03055013) and pembrolizumab (NCT03142334), which could be beneficial to these tumors at high risk of recurrence.

\section{Conclusions}

Clinical and translational research efforts have transformed the understanding of sRCC: from a hard-to-treat disease with limited biological understanding, it is becoming part of a burgeoning research field with major advances in outcomes and new paths to innovative therapeutic developments. Evaluation of novel treatment strategies and potential biomarkers of response to therapy are needed to improve patient selection and the prognosis of this aggressive disease.

Funding: This research received no external funding.

Conflicts of Interest: The authors declare no conflict of interest related to this work.

\section{References}

1. Bray, F.; Ferlay, J.; Soerjomataram, I.; Siegel, R.L.; Torre, L.A.; Jemal, A. Global cancer statistics 2018: GLOBOCAN estimates of incidence and mortality worldwide for 36 cancers in 185 countries. CA Cancer J. Clin. 2018, 68, 394-424. [CrossRef] [PubMed]

2. Kyriakopoulos, C.E.; Chittoria, N.; Choueiri, T.K.; Kroeger, N.; Lee, J.-L.; Srinivas, S.; Knox, J.J.; Bjarnason, G.A.; Ernst, S.D.; Wood, L.A.; et al. Outcome of patients with metastatic sarcomatoid renal cell carcinoma: Results from the International Metastatic Renal Cell Carcinoma Database Consortium. Clin. Genitourin. Cancer 2015, 13, e79-e85. [CrossRef] [PubMed]

3. Albiges, L.; Flippot, R.; Rioux-Leclercq, N.; Choueiri, T.K. Non-Clear Cell Renal Cell Carcinomas: From Shadow to Light. J. Clin. Oncol. 2018, 36, 3624-3631. [CrossRef] [PubMed]

4. Kroeger, N.; Xie, W.; Lee, J.-L.; Bjarnason, G.A.; Knox, J.J.; Mackenzie, M.J.; Wood, L.; Srinivas, S.; Vaishamayan, U.N.; Rha, S.-Y.; et al. Metastatic non-clear cell renal cell carcinoma treated with targeted therapy agents: Characterization of survival outcome and application of the International mRCC Database Consortium criteria. Cancer 2013, 119, 2999-3006. [CrossRef] [PubMed]

5. Molina, A.M.; Tickoo, S.K.; Ishill, N.; Trinos, M.J.; Schwartz, L.H.; Patil, S.; Feldman, D.R.; Reuter, V.E.; Russo, P.; Motzer, R.J. Sarcomatoid-variant Renal Cell Carcinoma Treatment Outcome and Survival in Advanced Disease. Am. J. Clin. Oncol. 2011, 34, 454-459. [CrossRef] [PubMed]

6. Zhang, L.; Wu, B.; Zha, Z.; Zhao, H.; Feng, Y. The prognostic value and clinicopathological features of sarcomatoid differentiation in patients with renal cell carcinoma: A systematic review and meta-analysis. Cancer Manag. Res. 2018, 10, 1687-1703. [CrossRef]

7. Moch, H.; Cubilla, A.L.; Humphrey, P.A.; Reuter, V.E.; Ulbright, T.M. The 2016 WHO Classification of Tumours of the Urinary System and Male Genital Organs-Part A: Renal, Penile, and Testicular Tumours. Eur. Urol. 2016, 70, 93-105. [CrossRef]

8. He, H.; Magi-Galluzzi, C. Epithelial-to-mesenchymal transition in renal neoplasms. Adv. Anat. Pathol. 2014, 21, 174-180. [CrossRef] 
9. Boström, A.-K.; Möller, C.; Nilsson, E.; Elfving, P.; Axelson, H.; Johansson, M.E. Sarcomatoid conversion of clear cell renal cell carcinoma in relation to epithelial-to-mesenchymal transition. Hum. Pathol. 2012, 43, 708-719. [CrossRef]

10. Conant, J.L.; Peng, Z.; Evans, M.F.; Naud, S.; Cooper, K. Sarcomatoid renal cell carcinoma is an example of epithelial-mesenchymal transition. J. Clin. Pathol. 2011, 64, 1088-1092. [CrossRef]

11. Yu, W.; Wang, Y.; Jiang, Y.; Zhang, W.; Li, Y. Distinct immunophenotypes and prognostic factors in renal cell carcinoma with sarcomatoid differentiation: A systematic study of 19 immunohistochemical markers in 42 cases. BMC Cancer 2017, 17, 293. [CrossRef] [PubMed]

12. Reuter, V.E.; Argani, P.; Zhou, M.; Delahunt, B. Members of the ISUP Immunohistochemistry in Diagnostic Urologic Pathology Group Best practices recommendations in the application of immunohistochemistry in the kidney tumors: Report from the International Society of Urologic Pathology consensus conference. Am. J. Surg. Pathol. 2014, 38, e35-e49. [PubMed]

13. Tanas Isikci, O.; He, H.; Grossmann, P.; Alaghehbandan, R.; Ulamec, M.; Michalova, K.; Pivovarcikova, K.; Montiel, D.P.; Ondic, O.; Daum, O.; et al. Low-grade spindle cell proliferation in clear cell renal cell carcinoma is unlikely to be an initial step in sarcomatoid differentiation. Histopathology 2018, 72, 804-813. [CrossRef] [PubMed]

14. Delahunt, B.; Srigley, J.R.; Egevad, L.; Montironi, R. International Society of Urological Pathology Grading and Other Prognostic Factors for Renal Neoplasia. Eur. Urol. 2014, 66, 795-798. [CrossRef] [PubMed]

15. Warren, A.Y.; Harrison, D. WHO/ISUP classification, grading and pathological staging of renal cell carcinoma: Standards and controversies. World J. Urol. 2018, 36, 1913-1926. [CrossRef]

16. Cheville, J.C.; Lohse, C.M.; Zincke, H.; Weaver, A.L.; Leibovich, B.C.; Frank, I.; Blute, M.L. Sarcomatoid Renal Cell Carcinoma. Am. J. Surg. Pathol. 2004, 28, 7. [CrossRef]

17. Adibi, M.; Thomas, A.Z.; Borregales, L.D.; Merrill, M.M.; Slack, R.S.; Chen, H.-C.; Sircar, K.; Murugan, P.; Tamboli, P.; Jonasch, E.; et al. Percentage of sarcomatoid component as a prognostic indicator for survival in renal cell carcinoma with sarcomatoid dedifferentiation. Urol. Oncol. 2015, 33, 427.e17-427.e23. [CrossRef]

18. Alevizakos, M.; Gaitanidis, A.; Nasioudis, D.; Msaouel, P.; Appleman, L.J. Sarcomatoid Renal Cell Carcinoma: Population-Based Study of 879 Patients. Clin. Genitourin. Cancer 2019, 17, e447-e453. [CrossRef]

19. Shuch, B.; Said, J.; LaRochelle, J.C.; Zhou, Y.; Li, G.; Klatte, T.; Pouliot, F.; Kabbinavar, F.F.; Belldegrun, A.S.; Pantuck, A.J. Histologic evaluation of metastases in renal cell carcinoma with sarcomatoid transformation and its implications for systemic therapy. Cancer 2010, 116, 616-624. [CrossRef]

20. Abel, E.J.; Culp, S.H.; Matin, S.F.; Tamboli, P.; Wallace, M.J.; Jonasch, E.; Tannir, N.M.; Wood, C.G. Percutaneous biopsy of primary tumor in metastatic renal cell carcinoma to predict high risk pathological features: Comparison with nephrectomy assessment. J. Urol. 2010, 184, 1877-1881. [CrossRef]

21. Jones, T.D.; Eble, J.N.; Wang, M.; MacLennan, G.T.; Jain, S.; Cheng, L. Clonal divergence and genetic heterogeneity in clear cell renal cell carcinomas with sarcomatoid transformation. Cancer 2005, 104, 1195-1203. [CrossRef] [PubMed]

22. Sircar, K.; Yoo, S.-Y.; Majewski, T.; Wani, K.; Patel, L.R.; Voicu, H.; Torres-Garcia, W.; Verhaak, R.G.W.; Tannir, N.; Karam, J.A.; et al. Biphasic components of sarcomatoid clear cell renal cell carcinomas are molecularly similar to each other, but distinct from, non-sarcomatoid renal carcinomas. J. Pathol. Clin. Res. 2015, 1, 212-224. [CrossRef] [PubMed]

23. Bi, M.; Zhao, S.; Said, J.W.; Merino, M.J.; Adeniran, A.J.; Xie, Z.; Nawaf, C.B.; Choi, J.; Belldegrun, A.S.; Pantuck, A.J.; et al. Genomic characterization of sarcomatoid transformation in clear cell renal cell carcinoma. Proc. Natl. Acad. Sci. USA 2016, 113, 2170-2175. [CrossRef] [PubMed]

24. Wang, Z.; Kim, T.B.; Peng, B.; Karam, J.A.; Creighton, C.J.; Joon, A.Y.; Kawakami, F.; Trevisan, P.; Jonasch, E.; Chow, C.-W.; et al. Sarcomatoid renal cell carcinoma has a distinct molecular pathogenesis, driver mutation profile and transcriptional landscape. Clin. Cancer Res. 2017, 23, 6686-6696. [CrossRef]

25. Brannon, A.R.; Reddy, A.; Seiler, M.; Arreola, A.; Moore, D.T.; Pruthi, R.S.; Wallen, E.M.; Nielsen, M.E.; Liu, H.; Nathanson, K.L.; et al. Molecular Stratification of Clear Cell Renal Cell Carcinoma by Consensus Clustering Reveals Distinct Subtypes and Survival Patterns. Genes Cancer 2010, 1, 152-163. [CrossRef]

26. Pal, S.K.; He, M.; Tong, T.; Wu, H.; Liu, X.; Lau, C.; Wang, J.-H.; Warden, C.; Wu, X.; Signoretti, S.; et al. RNA-seq reveals aurora kinase-driven $\mathrm{mTOR}$ pathway activation in patients with sarcomatoid metastatic renal cell carcinoma. Mol. Cancer Res. MCR 2015, 13, 130-137. [CrossRef] 
27. Malouf, G.G.; Ali, S.M.; Wang, K.; Balasubramanian, S.; Ross, J.S.; Miller, V.A.; Stephens, P.J.; Khayat, D.; Pal, S.K.; Su, X.; et al. Genomic Characterization of Renal Cell Carcinoma with Sarcomatoid Dedifferentiation Pinpoints Recurrent Genomic Alterations. Eur. Urol. 2016, 70, 348-357. [CrossRef]

28. The Cancer Genome Atlas Research Network Comprehensive molecular characterization of clear cell renal cell carcinoma. Nature 2013, 499, 43-49. [CrossRef]

29. Ricketts, C.J.; Cubas, A.A.D.; Fan, H.; Smith, C.C.; Lang, M.; Reznik, E.; Bowlby, R.; Gibb, E.A.; Akbani, R.; Beroukhim, R.; et al. The Cancer Genome Atlas Comprehensive Molecular Characterization of Renal Cell Carcinoma. Cell Rep. 2018, 23, 313-326.e5. [CrossRef]

30. Chen, Y.-B.; Xu, J.; Skanderup, A.J.; Dong, Y.; Brannon, A.R.; Wang, L.; Won, H.H.; Wang, P.I.; Nanjangud, G.J.; Jungbluth, A.A.; et al. Molecular analysis of aggressive renal cell carcinoma with unclassified histology reveals distinct subsets. Nat. Commun. 2016, 7, 13131. [CrossRef]

31. White, S.M.; Avantaggiati, M.L.; Nemazanyy, I.; Di Poto, C.; Yang, Y.; Pende, M.; Gibney, G.T.; Ressom, H.W.; Field, J.; Atkins, M.B.; et al. YAP/TAZ Inhibition Induces Metabolic and Signaling Rewiring Resulting in Targetable Vulnerabilities in NF2-Deficient Tumor Cells. Dev. Cell 2019, 49, 425-443.e9. [CrossRef] [PubMed]

32. Kawakami, F.; Sircar, K.; Rodriguez-Canales, J.; Fellman, B.M.; Urbauer, D.L.; Tamboli, P.; Tannir, N.M.; Jonasch, E.; Wistuba, I.I.; Wood, C.G.; et al. Programmed cell death ligand 1 and tumor-infiltrating lymphocyte status in patients with renal cell carcinoma and sarcomatoid dedifferentiation. Cancer 2017, 123, 4823-4831. [CrossRef] [PubMed]

33. Joseph, R.W.; Millis, S.Z.; Carballido, E.M.; Bryant, D.; Gatalica, Z.; Reddy, S.; Bryce, A.H.; Vogelzang, N.J.; Stanton, M.L.; Castle, E.P.; et al. PD-1 and PD-L1 Expression in Renal Cell Carcinoma with Sarcomatoid Differentiation. Cancer Immunol. Res. 2015, 3, 1303-1307. [CrossRef] [PubMed]

34. Flippot, R.; McGregor, B.A.; Flaifel, A.; Gray, K.P.; Signoretti, S.; Steinharter, J.A.; Van Allen, E.M.; Walsh, M.K.; Gundy, K.; Wei, X.X.; et al. Atezolizumab plus bevacizumab in non-clear cell renal cell carcinoma (NccRCC) and clear cell renal cell carcinoma with sarcomatoid differentiation (ccRCCsd): Updated results of activity and predictive biomarkers from a phase II study. J. Clin. Oncol. 2019, 37, 4583. [CrossRef]

35. Rini, B.I.; Motzer, R.J.; Powles, T.; McDermott, D.F.; Escudier, B.; Donskov, F.; Hawkins, R.E.; Bracarda, S.; Bedke, J.; De Giorgi, U.; et al. Atezolizumab (atezo) + bevacizumab (bev) versus sunitinib (sun) in pts with untreated metastatic renal cell carcinoma (mRCC) and sarcomatoid (sarc) histology: IMmotion151 subgroup analysis. J. Clin. Oncol. 2019, 37, 4512. [CrossRef]

36. 3Efficacy and biomarker analysis of patients (pts) with advanced renal cell carcinoma (aRCC) with sarcomatoid histology (sRCC): Subgroup analysis fr... Available online: https://oncologypro.esmo. org/Meeting-Resources/ESMO-2019-Congress/Efficacy-and-biomarker-analysis-of-patients-pts-withadvanced-renal-cell-carcinoma-aRCC-with-sarcomatoid-histology-sRCC-subgroup-analysis-from-thephase-3-JAVELIN-Renal-101-trial-of-first-line-avelumab-plus-axitinib-A-Ax-vs-sunitinib-S (accessed on 30 September 2019).

37. Rini, B.I.; Powles, T.; Atkins, M.B.; Escudier, B.; McDermott, D.F.; Suarez, C.; Bracarda, S.; Stadler, W.M.; Donskov, F.; Lee, J.L.; et al. Atezolizumab plus bevacizumab versus sunitinib in patients with previously untreated metastatic renal cell carcinoma (IMmotion151): A multicentre, open-label, phase 3, randomised controlled trial. Lancet 2019, 393, 2404-2415. [CrossRef]

38. Samstein, R.M.; Lee, C.-H.; Shoushtari, A.N.; Hellmann, M.D.; Shen, R.; Janjigian, Y.Y.; Barron, D.A.; Zehir, A.; Jordan, E.J.; Omuro, A.; et al. Tumor mutational load predicts survival after immunotherapy across multiple cancer types. Nat. Genet. 2019, 51, 202-206. [CrossRef]

39. Bakouny, Z.; Vokes, N.; Gao, X.; Nassar, A.; Abou Alaiwi, S.; Flippot, R.; Bouchard, G.; Steinharter, J.A.; Nuzzo, P.; Pan, W.; et al. Efficacy of immune checkpoint inhibitors (ICI) and genomic characterization of sarcomatoid and/or rhabdoid (S/R) metastatic renal cell carcinoma (mRCC). J. Clin. Oncol. 2019, 37, 4514. [CrossRef]

40. Binnewies, M.; Roberts, E.W.; Kersten, K.; Chan, V.; Fearon, D.F.; Merad, M.; Coussens, L.M.; Gabrilovich, D.I.; Ostrand-Rosenberg, S.; Hedrick, C.C.; et al. Understanding the tumor immune microenvironment (TIME) for effective therapy. Nat. Med. 2018, 24, 541-550. [CrossRef]

41. Turajlic, S.; Litchfield, K.; Xu, H.; Rosenthal, R.; McGranahan, N.; Reading, J.L.; Wong, Y.N.S.; Rowan, A.; Kanu, N.; Bakir, M.A.; et al. Insertion-and-deletion-derived tumour-specific neoantigens and the immunogenic phenotype: A pan-cancer analysis. Lancet Oncol. 2017, 18, 1009-1021. [CrossRef] 
42. Sharma, P.; Hu-Lieskovan, S.; Wargo, J.A.; Ribas, A. Primary, Adaptive and Acquired Resistance to Cancer Immunotherapy. Cell 2017, 168, 707-723. [CrossRef] [PubMed]

43. Golshayan, A.R.; George, S.; Heng, D.Y.; Elson, P.; Wood, L.S.; Mekhail, T.M.; Garcia, J.A.; Aydin, H.; Zhou, M.; Bukowski, R.M.; et al. Metastatic sarcomatoid renal cell carcinoma treated with vascular endothelial growth factor-targeted therapy. J. Clin. Oncol. Off. J. Am. Soc. Clin. Oncol. 2009, 27, 235-241. [CrossRef] [PubMed]

44. Haas, N.B.; Lin, X.; Manola, J.; Pins, M.; Liu, G.; McDermott, D.; Nanus, D.; Heath, E.; Wilding, G.; Dutcher, J. A phase II trial of doxorubicin and gemcitabine in renal cell carcinoma with sarcomatoid features: ECOG 8802. Med. Oncol. Northwood Lond. Engl. 2012, 29, 761-767. [CrossRef] [PubMed]

45. Maiti, A.; Nemati-Shafaee, M.; Msaouel, P.; Pagliaro, L.C.; Jonasch, E.; Tannir, N.M.; Shah, A.Y. Phase II Trial of Capecitabine, Gemcitabine, and Bevacizumab in Sarcomatoid Renal Cell Carcinoma. Clin. Genitourin. Cancer 2018, 16, e47-e57. [CrossRef] [PubMed]

46. Michaelson, M.D.; McKay, R.R.; Werner, L.; Atkins, M.B.; Van Allen, E.M.; Olivier, K.M.; Song, J.; Signoretti, S.; McDermott, D.F.; Choueiri, T.K. Phase 2 trial of sunitinib and gemcitabine in patients with sarcomatoid and/or poor-risk metastatic renal cell carcinoma. Cancer 2015, 121, 3435-3443. [CrossRef] [PubMed]

47. Motzer, R.J.; Tannir, N.M.; McDermott, D.F.; Arén Frontera, O.; Melichar, B.; Choueiri, T.K.; Plimack, E.R.; Barthélémy, P.; Porta, C.; George, S.; et al. Nivolumab plus Ipilimumab versus Sunitinib in Advanced Renal-Cell Carcinoma. N. Engl. J. Med. 2018, 378, 1277-1290. [CrossRef] [PubMed]

48. Rini, B.I.; Plimack, E.R.; Stus, V.; Gafanov, R.; Hawkins, R.; Nosov, D.; Pouliot, F.; Alekseev, B.; Soulières, D.; Melichar, B.; et al. Pembrolizumab plus Axitinib versus Sunitinib for Advanced Renal-Cell Carcinoma. N. Engl. J. Med. 2019, 380, 1116-1127. [CrossRef]

49. Rini, B.I.; Plimack, E.R.; Stus, V.; Gafanov, R.; Hawkins, R.; Nosov, D.; Pouliot, F.; Soulieres, D.; Melichar, B.; Vynnychenko, I.; et al. Pembrolizumab (pembro) plus axitinib (axi) versus sunitinib as first-line therapy for metastatic renal cell carcinoma (mRCC): Outcomes in the combined IMDC intermediate/poor risk and sarcomatoid subgroups of the phase 3 KEYNOTE-426 study. J. Clin. Oncol. 2019, 37, 4500. [CrossRef]

50. Gauci, M.-L.; Lanoy, E.; Champiat, S.; Caramella, C.; Ammari, S.; Aspeslagh, S.; Varga, A.; Baldini, C.; Bahleda, R.; Gazzah, A.; et al. Long-Term Survival in Patients Responding to Anti-Pd-1/Pd-L1 Therapy and Disease Outcome Upon Treatment Discontinuation. Clin. Cancer Res. 2019, 25, 946-956. [CrossRef]

51. First-Line Pembrolizumab (pembro) Monotherapy for Advanced Non-Clear Cell Renal Cell Carcinoma (nccRCC): Updated Follow-Up for KEYNOTE-427 Cohort B. Available online: https://oncologypro.esmo.org/Meeting-Resources/ESMO-2019-Congress/First-Line-Pembrolizumabpembro-Monotherapy-for-Advanced-Non-Clear-Cell-Renal-Cell-Carcinoma-nccRCC-Updated-FollowUp-for-KEYNOTE-427-Cohort-B (accessed on 30 September 2019).

52. Jung, H.-Y.; Fattet, L.; Yang, J. Molecular Pathways: Linking Tumor Microenvironment to Epithelial-Mesenchymal Transition in Metastasis. Clin. Cancer Res. Off. J. Am. Assoc. Cancer Res. 2015, 21, 962-968. [CrossRef]

53. Flippot, R.; Beinse, G.; Boilève, A.; Vibert, J.; Malouf, G.G. Long non-coding RNAs in genitourinary malignancies: A whole new world. Nat. Rev. Urol. 2019, 16, 484-504. [CrossRef] [PubMed]

54. Motzer, R.J.; Penkov, K.; Haanen, J.; Rini, B.; Albiges, L.; Campbell, M.T.; Venugopal, B.; Kollmannsberger, C.; Negrier, S.; Uemura, M.; et al. Avelumab plus Axitinib versus Sunitinib for Advanced Renal-Cell Carcinoma. N. Engl. J. Med. 2019, 380, 1103-1115. [CrossRef] [PubMed]

55. Rini, B.I.; Huseni, M.; Atkins, M.B.; McDermott, D.F.; Powles, T.B.; Escudier, B.; Banchereau, R.; Liu, L.-F.; Leng, N.; Fan, J.; et al. LBA31Molecular correlates differentiate response to atezolizumab (atezo) + bevacizumab (bev) vs sunitinib (sun): Results from a phase III study (IMmotion151) in untreated metastatic renal cell carcinoma (mRCC). Ann. Oncol. 2018, 29, mdy424-037. [CrossRef]

56. Bentebibel, S.-E.; Hurwitz, M.E.; Bernatchez, C.; Haymaker, C.; Hudgens, C.W.; Kluger, H.M.; Tetzlaff, M.T.; Tagliaferri, M.A.; Zalevsky, J.; Hoch, U.; et al. A First-in-Human Study and Biomarker Analysis of NKTR-214, a Novel IL2R $\beta \gamma$-Biased Cytokine, in Patients with Advanced or Metastatic Solid Tumors. Cancer Discov. 2019, 9, 711-721. [CrossRef] [PubMed]

57. Flippot, R.; Escudier, B.; Albiges, L. Immune Checkpoint Inhibitors: Toward New Paradigms in Renal Cell Carcinoma. Drugs 2018, 78, 1443-1457. [CrossRef] [PubMed] 
58. Theelen, W.S.M.E.; Peulen, H.M.U.; Lalezari, F.; van der Noort, V.; de Vries, J.F.; Aerts, J.G.J.V.; Dumoulin, D.W.; Bahce, I.; Niemeijer, A.-L.N.; de Langen, A.J.; et al. Effect of Pembrolizumab After Stereotactic Body Radiotherapy vs Pembrolizumab Alone on Tumor Response in Patients with Advanced Non-Small Cell Lung Cancer: Results of the PEMBRO-RT Phase 2 Randomized Clinical Trial. JAMA Oncol. 2019, 5, 1276-1282. [CrossRef] [PubMed]

59. Pal, S.K.; Ali, S.M.; Ross, J.; Choueiri, T.K.; Chung, J.H. Exceptional Response to Palbociclib in Metastatic Collecting Duct Carcinoma Bearing a CDKN2A Homozygous Deletion. JCO Precis. Oncol. 2017, 1, 1-5. [CrossRef]

60. Alldredge, J.K.; Eskander, R.N. EZH2 inhibition in ARID1A mutated clear cell and endometrioid ovarian and endometrioid endometrial cancers. Gynecol. Oncol. Res. Pract. 2017, 4, 17. [CrossRef]

(C) 2019 by the authors. Licensee MDPI, Basel, Switzerland. This article is an open access article distributed under the terms and conditions of the Creative Commons Attribution (CC BY) license (http://creativecommons.org/licenses/by/4.0/). 